\title{
Poly(ethylene terephthalate) Polymer Surfaces as a Substrate for Bacterial Attachment and Biofilm Formation
}

\author{
Hayden K. WebB ${ }^{1}$, Russell J. CraWford ${ }^{1}$, TOMOO SAWABE ${ }^{2}$, and Elena P. IVANOva ${ }^{1 *}$ \\ ${ }^{1}$ Swinburne University of Technology, Faculty of Life and Social Sciences, P. O. Box 218, Hawthorn, Vic 3122, \\ Australia; and ${ }^{2}$ Laboratory of Microbiology, Faculty of Fisheries Sciences, Hokkaido University, 3-1-1 Minato-cho, \\ Hakodate 041-8611, Japan
}

(Received August 27, 2008-Accepted November 30, 2008—Published online December 19, 2008)

Plastic debris causes extensive damage to the marine environment, largely due to its ability to resist degradation. Attachment on plastic surfaces is a key initiation process for their degradation. The tendency of environmental marine bacteria to adhere to poly(ethylene terephthalate) (PET) plastic surfaces as a model material was investigated. It was found that the overall number of heterotrophic bacteria in a sample of sea water taken from St. Kilda Beach, Melbourne, Australia, was significantly reduced after six months from $4.2-4.7 \times 10^{3} \mathrm{cfu} \mathrm{mL}^{-1}$ to below detectable levels on both full-strength and oligotrophic marine agar plates. The extinction of oligotrophs after six months was detected in all samples. In contrast, the overall bacterial number recovered on full strength marine agar from the sample flasks with PET did not dramatically reduce. Heterotrophic bacteria recovered on full-strength marine agar plates six months after the commencement of the experiment were found to have suitable metabolic activity to survive in sea water while attaching to the PET plastic surface followed by the commencement of biofilm formation.

Key words: poly(ethylene terephthalate), bacterial attachment, biofilm

Plastic debris in the environment causes considerable damage, especially in marine environments. The ability of plastic to persist is the major factor behind the danger posed Zheng et al. (17). A number of beaches around the world are symptomatic of the high degree of pollution of the ocean by plastic particles (15). As plastic tends to float, it is easily transported by ocean currents and tends to accumulate on beaches, often thousands of kilometres from its place of origin (15). However the rest of the ocean is not immune. A study of plastic levels in the open ocean compared plastic particles to zooplankton in terms of number and in mass (14). Zooplankton was found to outnumber plastic particles five to one, however plastic outweighed zooplankton six to one. This discrepancy is of particular importance when considering marine wildlife. Many animals, including marine birds (4), sea turtles (3), and cetaceans (2) often mistake plastic objects for food. Ingested plastic persists in the digestive tract, and leads to lower feeding stimuli, gastrointestinal blockage, and reproductive problems (1). Other dangers associated with plastic debris include entanglement in larger objects (6), absorption of toxic chemicals such as polychlorinated biphenyls (PCBs) and nonylphenol (16), and transportation of non-indigenous harmful algal blooms (HAB) (12).

There are currently three main strategies employed for disposal of plastic waste: Landfill, incineration, and recycling (17). Each has its own inherent limitations. Disposal via land fill occupies space and has potential for polluting groundwater. Similarly, incineration leads to the production of secondary pollutants which are then released into the atmosphere. Recycling addresses these shortcomings, but is a much more expensive process. Also many plastic materials are unsuitable for recycling.

\footnotetext{
* Corresponding author. E-mail: eivanova@swin.edu.au; Tel: +613-9214-5137; Fax: +61-3-9819-0834.
}

Many plastic materials, such as the material used for most soft-drink and water bottles poly(ethylene terephthalate) (PET), are specifically designed to be physically and chemically durable, and a component of this is microbial resistance (17). As a result most microbes will preferentially associate with other, more nutrient-rich surfaces. The current study aims to investigate the capability of bacteria from the marine environment to associate with and adhere to the surface of a common plastic packaging material, namely PET. Understanding the factors that influence bacterial attachment on plastic surfaces will be useful for promoting bacterial growth on such substrates in order to better facilitate their biodegradation. Ultimately, it is hoped that a methodology for biodegradation of plastic in the environment can be developed.

\section{Materials and Methods}

Isolation procedure

A sample of seawater was taken from Port Phillip Bay, Melbourne, at St. Kilda beach on December 12, 2007. One hundred and two hundred millilitres respectively were placed in two conical flasks designated 1 and 2. To these flasks five and ten grams, respectively, of PET was added. The plastic was prepared by cutting plastic bottles (Mount Franklin water, Coca-Cola Amatil, Sydney, Australia, $400 \mathrm{~mL}$ ) into approximately $1 \mathrm{~cm}^{2}$ pieces and sterilised with $70 \%$ ethanol. These flasks were left at room temperature to allow bacteria in the sample opportunity to attach to the plastic and initiate biofilm formation. The seawater remaining in the collection vessel was retained as a control, i.e. seawater with no plastic.

Ten $\mu \mathrm{L}$ of the initial sample of seawater was cultured on marine agar plates (Difco, Sparks, USA). In addition to full strength agar plates, one-tenth agar was also used to cater for potential oligotrophic bacteria. The isolation of viable bacteria was repeated for sample flasks 1 and 2 after three and six months. The total number of recovered heterotrophic bacteria was evaluated by direct counting. Characteristic individual colonies were further selected and pure cultures obtained. Pure cultures were stored at $-80^{\circ} \mathrm{C}$ in marine broth 2216 (Difco, Sparks, USA) supplemented with 20\% (v/v) of glycerol. 


\section{Plastic surface characterisation}

Plastic surface wettability was measured using an FTA1000 (First Ten Ångstroms, Portsmouth, USA). Contact angles for three diagnostic liquids of varying hydrophobicity were recorded for original plastic surfaces before the experiment and after six months of the experiment. Three separate measurements were taken and the results averaged (Table 1). These average values were used to calculate surface free energy of the plastic via the acid/base method (11). Biofilms were removed from the surfaces by washing with weak detergent and rinsing thoroughly to remove all traces of surfactant.

The plastic surface was also subjected to analysis by a scanning probe microscope (SPM) (Solver P7LS, NT-MDT, Nuenen, Netherlands). At the same time, a quantitative analysis of the surface roughness were conducted. The analysis was performed in the semicontact mode which reduces the interaction between the tip and the sample and thus allows the destructive action of lateral forces that exist in contact mode to be avoided. The carbon "whisker" type silicon cantilevers (NSC05, NT-MDT, Nuenen, Netherlands) with a spring constant of $11 \mathrm{~N} \mathrm{~m}^{-1}$, tip radius of curvature of $10 \mathrm{~nm}$, aspect ratio of 10:1 and resonance frequency of $150 \mathrm{KHz}$ were used to obtain good topographic resolution. Scanning was performed perpendicular to the axis of the cantilever at a typical rate of $1 \mathrm{~Hz}$. Image processing of the raw topographical data was performed with first order horizontal and vertical levelling and the topography and surface profile of the samples were obtained simultaneously. In this way the surface features of the samples were measured with a resolution of a fraction of nanometer and the surface roughness of the investigated areas (Fig. 1) could be statistically analysed using the standard instrument software (LS7-SPM v.8.58, NT-MDT, Nuenen, Netherlands).

\section{Imaging techniques}

The Confocal Scanning Laser Microscope (CSLM) used was the FluoView $^{\mathrm{TM}}$ FV1000 Spectroscopic Confocal System (Olympus, Tokyo, Japan) which included an inverted Microscope System
Olympus IX81 (20X, 40X (oil), 100X (oil) UIS objectives) which operates using multi $\mathrm{Ar}$ and HeNe lasers (458, 488, 515, 543, 633 $\mathrm{nm})$. The system is equipped with a transmitted light differential interference contract attachment and a CCD camera (Cool View FDI, Photonic Science, Robertsbridge, UK). Two fluorescent dyes were utilised in order to simultaneously visualize viable cells and their production of extracellular polymeric substances while attaching to the plastic surface. Vybrant CFDA SE Cell Tracer Kit (Invitrogen, Carlsbad, USA) was used to colour viable cells and Concanavalin A 488 (Invitrogen, Carlsbad, USA) was used to label EPS.

In order to assess bacterial attachment and growth, individual pieces of plastic were aseptically taken from the sample flasks periodically. Staining was performed as described elsewhere (13).

\section{Results}

The surface characteristics of the PET plastic surfaces tested were much as anticipated. The contact angle, $\theta$, of a water droplet resting on the surface was relatively high, indicating a reluctance to spread across the polymer surface, while conversely diiodomethane droplets tended to spread more and record a lower contact angle (Table 1). This is as expected of a polymeric material with a primarily hydrocarbon backbone. The recorded contact angle for water $\left(81.1^{\circ}\right)$ matched the value given in previous literature (7) very closely, while the value recorded for formamide $\left(58.7^{\circ}\right)$ differed by approx. $3^{\circ}$. The measured angle for diiodomethane $\left(28.8^{\circ}\right)$ differed from the literature value $(7)$ by $10^{\circ}$. The interfacial tension of the sample was calculated to be 44.26 dynes $\mathrm{cm}^{-1}$, which is close to the literature value of 43.0 (7). Notably, after bacterial attachment, the water contact angle did not change, however

Table 1. PET plastic surface wettability and surface free energy

\begin{tabular}{|c|c|c|c|c|c|c|c|c|}
\hline \multirow{2}{*}{ Surfaces $^{\#}$} & \multicolumn{3}{|c|}{ Contact angle $\theta\left({ }^{\circ}\right)^{*}$} & \multicolumn{5}{|c|}{ Surface free energy $\gamma\left(\mathrm{mJ} \mathrm{m}^{-2}\right)^{* *}$} \\
\hline & $\theta_{\mathrm{W}}$ & $\theta_{\mathrm{F}}$ & $\theta_{\mathrm{D}}$ & $\gamma^{\mathrm{LW}}$ & $\gamma^{\mathrm{AB}}$ & $\gamma^{+}$ & $\gamma^{-}$ & $\gamma_{\text {Tот }}$ \\
\hline Initial poly(ethylene terephthalate) polymer surfaces & $81.1 \pm 0.5$ & $58.7 \pm 0.3$ & $28.8 \pm 0.3$ & 44.3 & 0 & 0 & 5.2 & 44.3 \\
\hline Experimental poly(ethylene terephthalate) polymer surfaces ${ }^{\#}$ & $81.5 \pm 0.5$ & $62.1 \pm 0.3$ & $34.7 \pm 0.3$ & 41.1 & 0 & 0 & 6.9 & 41.1 \\
\hline
\end{tabular}

* Contact angle of water, formamide and diiodomethane $\left(\theta_{\mathrm{W}}, \theta_{\mathrm{F}}\right.$ and $\theta_{\mathrm{D}}$ respectively).

** Lifshitz/van der Waals component $\left(\gamma^{\mathrm{LW}}\right)$, acid/base component $\left(\gamma^{\mathrm{AB}}\right)$, electron acceptor $\left(\gamma^{+}\right)$and electron donor $\left(\gamma^{-}\right)$.

\# Experimental surfaces refers to PET surfaces after bacteria-surface interactions.

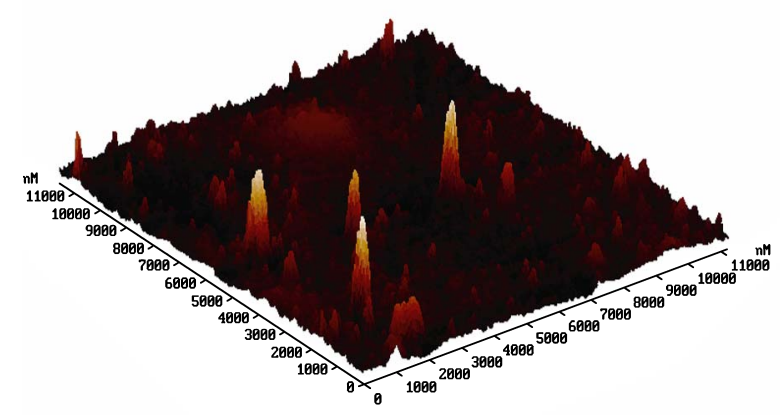

A
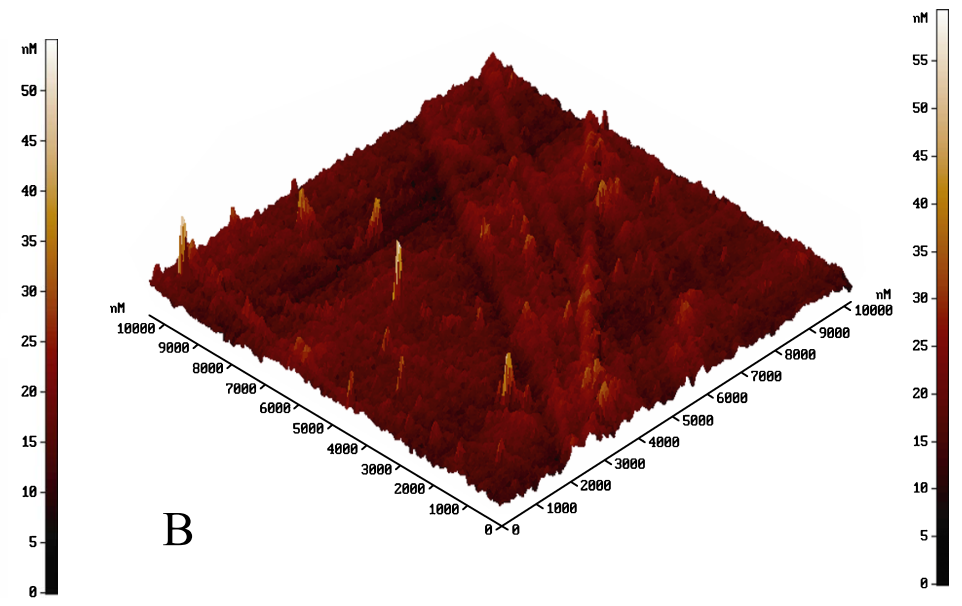

Fig. 1. Nanotopography of poly(ethylene terephthalate) polymer surfaces. Comparative AFM images of PET plastic surface topography of initial surface (A) and after bacteria-surface interactions (B). The areas scanned were approximately $10 \times 10 \mu \mathrm{m}$ in each case. Darker areas indicate lower laying points compared to the light peaks. High incidence of both light and dark is indicative of a particularly rough surface. 
the measured angles for formamide and diiodomethane increased contributing in resulting decrease of the interfacial tension.

AFM imaging showed the plastic surface topography was nano-smooth (Fig. 1A), with estimated surface average roughness $\left(R_{\mathrm{a}}\right)$ being in the range of $1.85 \pm 0.25 \mathrm{~nm}$, root mean square $\left(R_{\mathrm{q}}\right)$ of approximately $3.14 \pm 0.30 \mathrm{~nm}$, and max roughness $\left(R_{\max }\right)$ of $54.81 \pm 0.51 \mathrm{~nm}$. The topography of the plastic surface after bacterial attachment (Fig. 1B) has changed, becoming more nano-rough $\left(R_{\mathrm{a}}=2.45 \pm 0.22 \mathrm{~nm}\right.$, $\left.R_{\mathrm{q}}=3.30 \pm 0.25 \mathrm{~nm}, R_{\max }=60.20 \pm 0.55\right)$.

The results presented in Fig. 2 illustrate the bacterial populations recovered from the original sea water sample and from the sample flasks with and without PET after 6 months of the study. It follows from the results that the overall number of heterotrophic bacteria in the original sea water sample was significantly reduced after six months from $4.2-4.7 \times 10^{3}$ CFU $\mathrm{mL}^{-1}$ to below a detectable limit on both full-strength
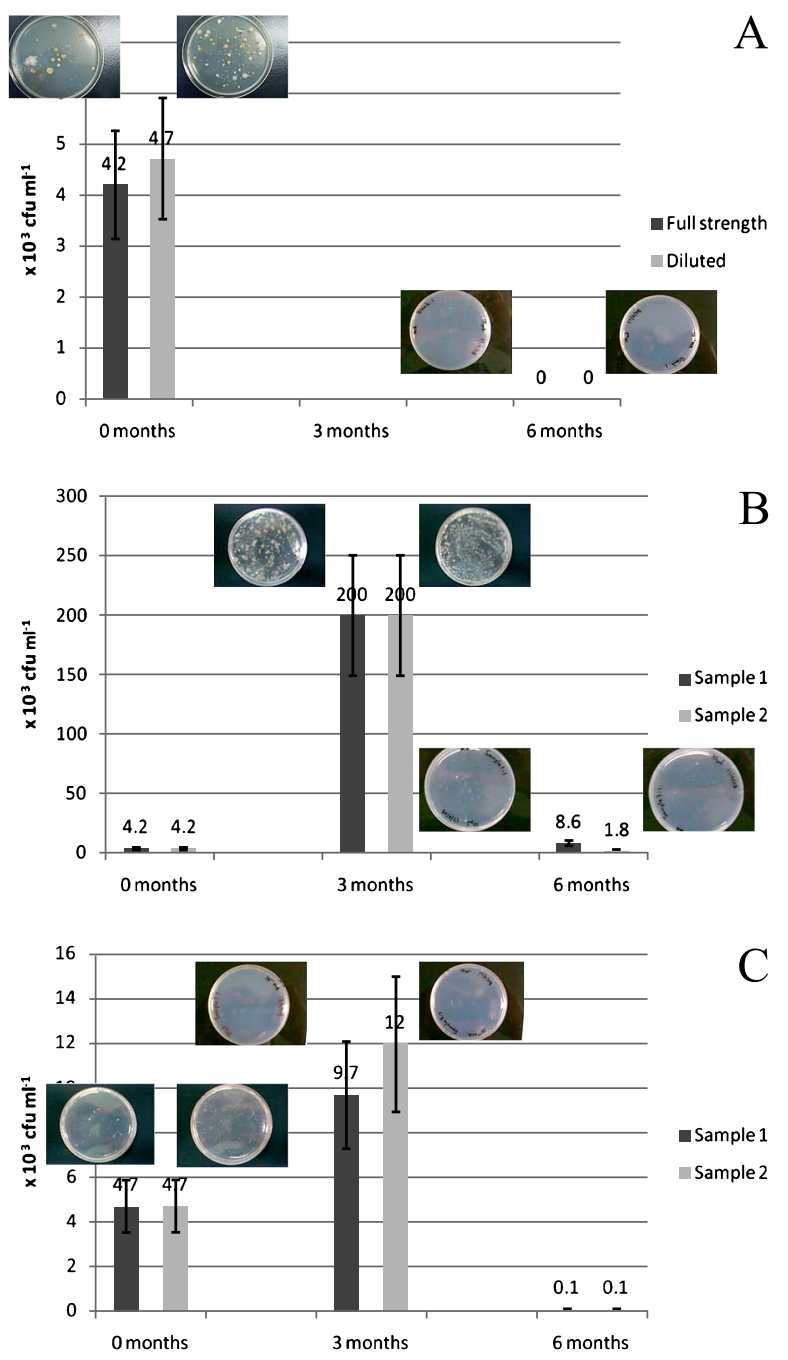

Fig. 2. Dynamics of cultivable bacterial populations in model experiments over six months. Sea water bacterial populations recovered on full-strength and oligotrophic marine agar (A); dynamics of bacterial populations grown on full-strength marine agar (B), shown for the flask sample 1 (S1) and for the flask sample 2 (S2); dynamics of bacterial populations grown on oligotrophic marine agar $(\mathrm{C})$, shown as above. Numbers on $\mathrm{Y}$ axis are $\mathrm{CFU} \mathrm{mL}^{-1} \times 10^{3}$. Inserts are selected typical plates with recovered bacteria. and oligotrophic marine agar; and in addition to this no bacteria were recovered from any sample on the oligotrophic media. In contrast, the overall number recovered from the full strength marine agar from the sample flasks with PET did not dramatically reduce. An initial increase in bacterial numbers in the sample flasks may possibly be attributed to limited nutrients naturally present in seawater. After six months bacterial colonies recovered on the full strength plates were primarily small, non-pigmented, translucent, and uniform, with a few that were slightly larger and yellow in colour. Notably, the number of pigmented colonies, after three months and again after six months decreased and only a

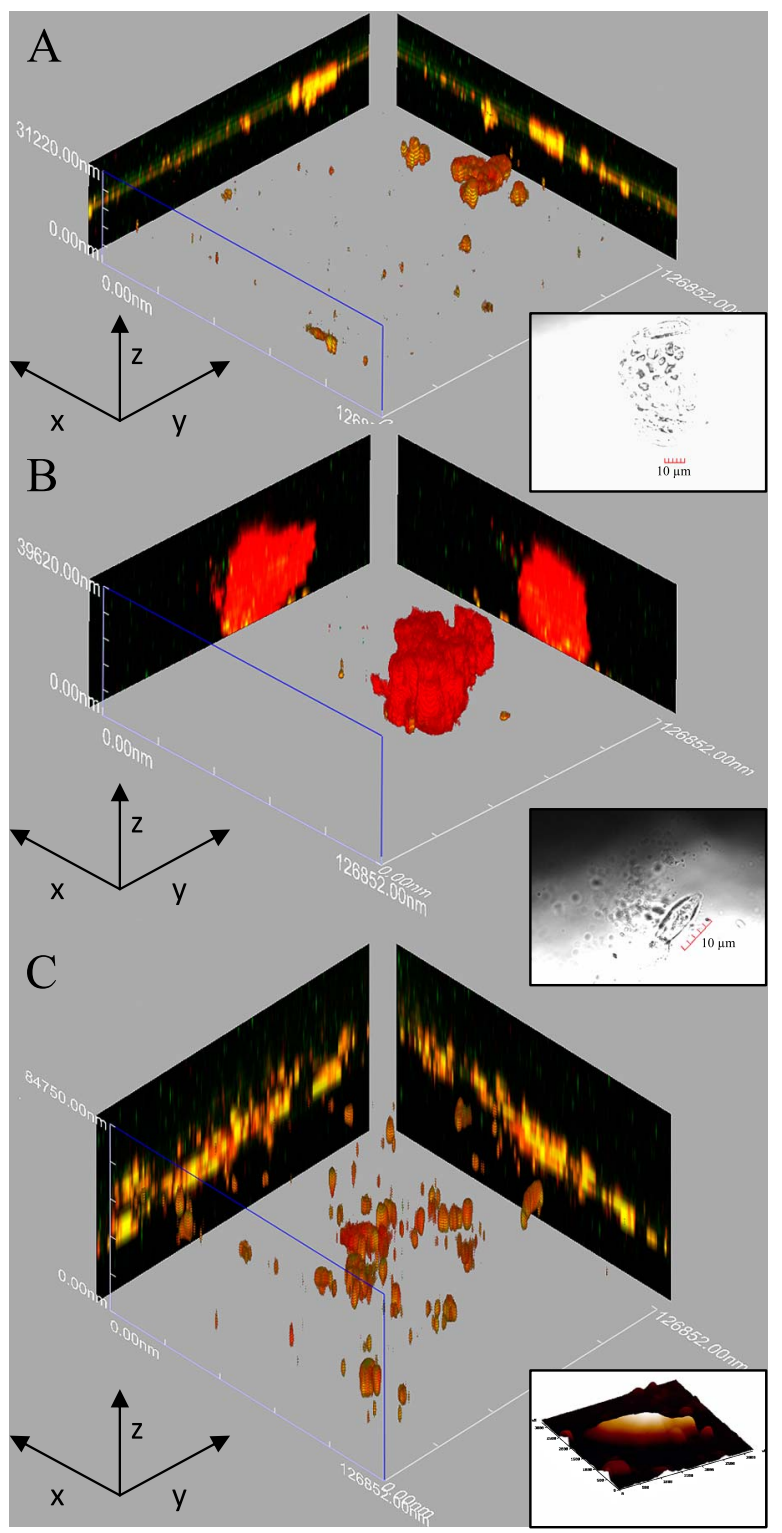

Fig. 3. Characteristic three-dimensional representations of bacterial growth and biofilm formation on PET plastic surfaces after a six-month model experiment visualised by the confocal scanning laser microscope (CSLM). Images indicated as A, B, C were taken from different areas of the same PET sample. Green areas indicate EPS, while red denotes viable cells. Yellow areas are the result of overlapping. Black and white images are corresponding phase contrast images for A and B areas, respectively. Inserted AFM image is that of bacterial cells attached to plastic surface corresponding to phase contrast image for $\mathrm{B}$ area. Scanning area is approximately $3 \mu \mathrm{m}^{2}$. 
few dominating phenotypes can be observed. Further work on the molecular characterisations of recovered bacterial populations is on the way.

The biofouling ability of bacterial populations residing in sea water was also monitored using confocal scanning laser microscope and atomic force microscopy. The confocal scanning laser microscope and atomic force microscopy images presented in Fig. 3 clearly show that after 6 months of the model experiment bacterial attachment to the PET plastic surface has occurred although to varying degrees. For example the growth pattern of bacterial association in Fig. 3 (A) is that of a thin and even biofilm of about $30 \mu \mathrm{m}$ in thickness. It appeared that bacterial attachment was more successful when numerous smaller cells are associated with larger cells, so that a large conglomerate (up to $40 \mu \mathrm{m}$ in thickness) of viable cells may survive as shown in Fig. 3 (B) and corresponding phase contrast and AFM images. Another type of a bacterial biofilm initiated on PET surface is also evident in Fig. 3 (C); it is much thicker (up to $90 \mu \mathrm{m}$ ) and somewhat patchy. Interestingly, in this case cells were observed with very little EPS production.

\section{Discussion}

For the purposes of this study a long-term model experiment has been designed to monitor the dynamics of growth and survival of cultivable bacterial populations over a period of six months in an oligotrophic marine environment. Polymeric PET was incorporated to act as a substratum for bacterial colonisation, biofilm formation and possible degradation. The control results as shown in Fig. 2 (A) indicated that no bacteria were recoverable after 6 months in the original sea water samples. The heterotrophic bacteria were only recovered (on full strength MA) from the water samples which contained PET. It also follows from the results obtained that bacterial populations residing in sea water were not only able to colonise PET plastic surfaces but also change the surface physico-chemical characteristics and topography, most likely due to the commencement of plastic degradation. It is noted that the interfacial tension of the PET plastic surfaces decreased, as evidenced by the increased contact angles for formamide and diiodomethane on the PET surface (Table 1). PET plastic surfaces became rough, but only on a nanometre scale (Fig. 1). This study highlights that bacteria contained in the initial water samples were able to survive under defined experimental conditions. Analysis of bacterial attachment patterns and biofilm formation as inferred from the confocal images suggest that bacteria might employ different attachment strategies while interacting with PET polymeric surfaces by producing or not producing EPS. It is believed that EPS production is essential in facilitating the initial stages of bacterial attachment to various surfaces $(8,13)$. Our recent studies on bacterial attachment to nanosmooth glass surfaces and to poly(tert-butyl methacrylate) $(\mathrm{P}(t \mathrm{BMA}))$ polymeric surfaces were in agreement with this concept: Enhanced bacterial attachment was accompanied by elevated levels of secreted extracellular polymeric materials $(9,10,13)$. In this study the shift in production of low amounts of EPS might be also due to the low carbon/nitrogen ratio as it was previously reported that EPS production is strongly dependent on the carbon/nitrogen ratio of the nutrient medium (5).

In conclusion, it is evident that environmental marine bac- teria have evolved metabolic pathways capable of enhancing their interactions with PET plastic surfaces. As a result of these interactions, environmental bacteria initiated biofilm formation, which may potentially be followed by degradation of the plastic. Some of the bacteria recovered may have potential as possible biodegraders of PET. In future, identification and characterisation of these bacteria may lead to a practical methodology for biodegradation of PET plastic in the environment. Indeed, usage of small portions of sea water in a laboratory flask as microcosms of the ocean may not include the processes influencing community structure such as grazing pressure exerted on phytoplankton by the macrozooplankton community and some other environmental factors. Nevertheless this type of experiments is of a considerable importance as a practical approach to assess a biodegradation potential of cultivable bacterial associations. This study also provided us the experimental demonstration of possible PET plastic biodegradation by environmental bacteria and further prospects for conducting the mesoscale enrichments to test the whole ecosystem response.

\section{References}

1. Azzarello, M.Y., and E.S. Van Vleet. 1987. Marine birds and plastic pollution. Mar. Ecol. Prog. Ser. 37:295-303.

2. Baird, R.W., and S.K. Hooker. 2000. Ingestion of plastic and unusual prey by a juvenile harbor porpoise. Mar. Pollut. Bull. 40:719-720.

3. Barreiros, J.P., and J. Barcelos. 2001. Plastic ingestion by a leatherback turtle Dermochelys coriacea from the Azores (NE Atlantic). Mar. Pollut. Bull. 42:1196-1197.

4. Blight, L.K., and A.E. Burger. 1997. Occurrence of plastic particles in sea birds from the eastern north Pacific. Mar. Pollut. Bull. 34:323325.

5. Degeest, B., and L. de Vuyst. 1999. Indication that the nitrogen source influences both amount and size of exopolysaccharides produced by Streptococcus thermophilus LY03 and modelling of the bacterial growth and exopolysaccharide production in a complex medium. Appl. Environ. Microbiol. 65:2863-2870.

6. Derraik, J.G.B. 2002. The pollution of the marine environment by plastic debris: a review. Mar. Pollut. Bull. 44:842-852.

7. Ellison, A.H., and W.A. Zisman. 1954. Wettability studies of nylon, polyethylene terephthalate and polystyrene. J. Phys. Chem. 58:503506.

8. Fletcher, M., and G.I. Loeb. 1979. Influence of substratum characteristics on the attachment of a marine pseudomonad to solid surfaces. Appl. Environ. Microbiol. 37:67-72.

9. Ivanova, E.P., N. Mitik-Dineva, R.C. Mocanasu, S. Murphy, J. Wang, G. van Reissen, and R.J. Crawford. 2008. V. fischeri and E. coli adhesion tendencies towards photolithographically modified nanosmooth poly(tert-butyl methacrylate) polymer surfaces. Open Access Nanosci Nanotech. 1:33-44.

10. Ivanova, E.P., N. Mitik-Dineva, J. Wang, D. Pham, J. Wright, D.V. Nicolau, R.C. Mocanasu, and R.J. Crawford. 2008. Staleya guttiformis attachment on poly(tert-butylmethacrylate) polymeric surfaces. Micron. 39:1197-1224

11. Liang, H., R. Xu, B.D. Favis, and H.P. Schreiber. 2000. Interfacial tension and acid-base approaches to polymer interactions. J. Polym. Sci. Pol. Phys. 38:2096-2104.

12. Masó, M., E. Garcés, F. Pagès, and J. Camp. 2003. Drifting plastic debris as a potential vector for harmful algal bloom (HAB) species. Sci. Mar. 67:107-111.

13. Mitik-Dineva, N., J. Wang, R.C. Mocanasu, P. Stoddard, R.J. Crawford, and E.P. Ivanova. 2008. Impact of nano-topography on bacterial attachment. Biotechnol. J. 3:536-544.

14. Moore, C.J., S.L. Moore, M.K. Leecaster, and S.B. Weisberg. 2001. A comparison of plastic and plankton in the north Pacific central gyre. Mar. Pollut. Bull. 42:1297-1300.

15. Morishige, C., M.J. Donohue, E. Flint, C. Swenson, and C. Woolaway. 2007. Factors affecting marine debris deposition at French Frigate Shoals, northwestern Hawaiian Islands marine national monument 1990-2006. Mar. Pollut. Bull. 54:1162-1169.

16. Rios, L.M., C. Moore, and P.R. Jones. 2007. Persistent organic pollutants carried by synthetic polymers in the ocean environment. Mar. Pollut. Bulletin. 54:1230-1237.

17. Zheng, Y., E.K. Yanful, and A.S. Bassi. 2005. A review of plastic waste biodegradation. Crit. Rev. Biotechnol. 25:243-250. 